\title{
Cyclical compressive stress induces differentiation of rat primary mandibular condylar chondrocytes through phosphorylated myosin light chain II
}

\author{
LIMIN LIU $^{1,2^{*}}$, LIN CHEN $^{1 *}$, ZHIHUI MAI $^{1}$, ZHULI PENG $^{1}$, KAFUNG YU $^{1}$, GUANQI LIU $^{1}$ and HONG AI ${ }^{1}$ \\ ${ }^{1}$ Department of Stomatology, The Third Affiliated Hospital of Sun Yat-sen University, \\ Guangzhou, Guangdong 510630; ${ }^{2}$ Department of Orthodontics, Zhujiang New Town Dental Clinic, \\ Hospital of Stomatology and Guangdong Provincial Key Laboratory of Stomatology, Guanghua School of Stomatology, \\ Sun Yat-sen University, Guangzhou, Guangdong 510055, P.R. China
}

Received September 15, 2015; Accepted September 5, 2016

DOI: $10.3892 / \mathrm{mmr} .2016 .5788$

\begin{abstract}
The role of myosin light chain II (MLC-II) in cellular differentiation of rat mandibular condylar chondrocytes (MCCs) induced by cyclical uniaxial compressive stress (CUCS) remains unclear. In the current study, a four-point bending system was used to apply CUCS to primary cultured MCCs from rats. It was identified that CUCS stimulated features of cellular differentiation including morphological alterations, cytoskeleton rearrangement and overproduction of proteoglycans. Furthermore, CUCS promoted runt-related transcription factor-2 (RUNX2) expression at mRNA $(\mathrm{P}<0.01)$ and protein levels $(\mathrm{P}<0.05)$ and elevated alkaline phosphatase (ALP) activity $(\mathrm{P}<0.01)$, which are both markers of osteogenic differentiation. Under conditions of stress, western blotting indicated that the ratio of phosphorylated MLC-II to total MLC-II was increased significantly $(\mathrm{P}<0.05)$. Silencing MLC-II by RNA interference reduced ALP activity $(\mathrm{P}<0.01)$, and eliminated RUNX2 mRNA expression $(\mathrm{P}<0.01)$. Addition of the MLC kinase inhibitor, ML-7, reduced the CUCS-associated upregulation of RUNX2 expression $(\mathrm{P}<0.01)$ and ALP activity $(\mathrm{P}<0.01)$. The data indicated that CUCS promoted cellular differentiation of rat primary MCCs, and this was suggested to be via the phosphorylation of MLC-II.
\end{abstract}

Correspondence to: Professor Hong Ai, Department of Stomatology, The Third Affiliated Hospital of Sun Yat-sen University, 600 Tianhe Road, Guangzhou, Guangdong 510630, P.R. China

E-mail: aih_zssy09@126.com

*Contributed equally

Key words: mandibular condylar chondrocyte, cyclical uniaxial compressive stress, myosin light chain II, RUNX2, cytoskeleton, cellular differentiation

\section{Introduction}

Cells sense external stimuli through the cytoskeleton, facilitated by actomyosin $(1,2)$. In conjunction with myosin, the cytoskeleton can exert traction on the surrounding matrix of cells or on adjacent cells, contributing to major alterations in cell morphology. In addition to sensing mechanical forces, the cytoskeleton can transform mechanical forces into biochemical signals. Due to the contractibility of the actin filaments, proteins associated with the cytoskeleton may be activated. Myosin II is the main non-muscle class of myosin, consisting of two sets of myosin heavy chains $(200 \mathrm{kDa})$ and two sets of myosin light chain (MLC; $16-20 \mathrm{kDa})$. MLC phosphorylation serves an important role in various cellular functions, including contraction and motility. MLC phosphorylation can be activated by MLC kinase (MLCK) (3).

The temporomandibular joint (TMJ) is functionally structured to withstand and adapt to mechanical loads (4-6). The loading condition of the TMJ has been reported to be primarily dynamic and compressive $(4,7)$. Comprising less than $10 \%$ of the cartilaginous tissue volume, chondrocytes can sense and respond to their mechanical environment $(5,8)$. They transduce extracellular stresses into intracellular signals, resulting in modulation of gene expression and cellular function, for example, proliferation, apoptosis, migration and remodeling. It was identified that loading conditions can be optimized to promote the maintenance of normal structure and function (9).

The mechanism of signal transduction of mandibular condylar chondrocytes (MCCs) following application of cyclical uniaxial compressive stress (CUCS) remains unclear. In the current study, a computer controlled four-point bending system was used to apply CUCS to the primary cultured chondrocytes. With this model, it was aimed to explore whether CUCS may promote differentiation of chondrocytes. The role of MLC-II in the mechanical stress-induced cellular differentiation of MCCs was investigated.

\section{Materials and methods}

MCC isolation and culture. The animal experiments were approved by the Committee on the Use of Live Animals in 
Teaching and Research of Sun Yat-sen University (Guangzhou, China). Neonatal Sprague-Dawley rats ( $n=75$; mean weight, $15 \pm 2.3 \mathrm{~g}$ ) were purchased from the Department of Laboratory Animal Science (Sun Yat-sen University). A total of 5 neonatal rats were used for each experiment. The mother rats were administered the standard pellet diet ab libitum, with one mother and baby in each cage. The rats were maintained in $12 \mathrm{~h} \mathrm{light/dark} \mathrm{cycles} \mathrm{at} \mathrm{a} \mathrm{temperature} \mathrm{of} 18-24^{\circ} \mathrm{C}$ and a relative humidity of $40-70 \%$.

Mandibular condylar cartilage was isolated from 7-day-old Sprague-Dawley rats. The rats were sacrificed using 200 $\mathrm{mg} / \mathrm{kg}$ sodium pentobarbital followed by cervical dislocation. Mandibular condylar cartilage was digested with $0.25 \%$ trypsin (Gibco; Thermo Fisher Scientific, Inc., Waltham, MA, USA) at $37^{\circ} \mathrm{C}$ for $30 \mathrm{~min}$. Subsequent to centrifugation for $5 \mathrm{~min}$ at $120 \mathrm{x} g$ at room temperature, mandibular condylar cartilages were digested with $0.02 \%$ type II collagenase (Invitrogen; Thermo Fisher Scientific, Inc.) in Dulbecco's modified Eagle's medium (DMEM; Sigma-Aldrich; Merck Millipore, Darmstadt, Germany) for $2 \mathrm{~h}$ at $37^{\circ} \mathrm{C}$. The supernatant was collected and centrifuged for $5 \mathrm{~min}$ at $120 \mathrm{x} g$ at room temperature. Primary condylar chondrocytes were rinsed three times. Subsequent to counting with a hemacytometer, cells were seeded in the culture dishes at a high density of $1.0 \times 10^{6}$ cells $/ \mathrm{cm}^{2}$ with DMEM with $10 \%$ fetal bovine serum (FBS; Gibco; Thermo Fisher Scientific, Inc.) and $1 \%$ penicillin-streptomycin-amphotericin $\mathrm{B}$ at $37^{\circ} \mathrm{C}$ in a humidified $5 \% \mathrm{CO}_{2}$-containing atmosphere. Passage 3 chondrocytes were seeded on the vinyl bending dishes at a density of $1.0 \times 10^{6}$ cells $/ \mathrm{cm}^{2}$ and used in the experiments.

Immunostaining. The chondrocytes were washed with cold phosphate-buffered saline (PBS) three times and were fixed in $4 \%$ formaldehyde for $15 \mathrm{~min}$ at room temperature. The primary anti-rabbit collagen type II antibody (ab34712; 1:100; Abcam, Cambridge, MA, USA) was used. A total of five images were randomly taken in each section under a light microscope (Olympus Corporation, Tokyo, Japan).

Alcian blue staining. Alcian blue staining was performed as described previously (10). In brief, the chondrocytes were fixed with paraformaldehyde $\left(4 \%, 4^{\circ} \mathrm{C}\right)$ for $20 \mathrm{~min}$, and after three washes with double distilled $\mathrm{H}_{2} \mathrm{O}\left(\mathrm{ddH}_{2} \mathrm{O}\right)$, alcian blue $(1 \%)$ in $3 \%$ acetic acid ( $\mathrm{pH} 2.5$ ) was used to stain for $30 \mathrm{~min}$ at room temperature. Thereafter, cells were washed with $\mathrm{ddH}_{2} \mathrm{O}$ three times and imaged by phase contrast microscopy (Olympus Corporation).

Application of CUCS with a four-point bending system. When the third passage of cells reached $70-80 \%$ confluence on the vinyl bending dishes made from cell culture dishes (Mirui; Chengdu MIRACLE Technology Co. Ltd., Sichuan, China), the cells were starved for $12 \mathrm{~h}$ in serum-free medium and then subjected to CUCS $(2,000 \mu$ strain for $2 \mathrm{~h})$ using a four-point bending system (Mirui, Sichuan, China), as described previously (11). Briefly, the device was designed based on beam deflection theory and the forces it supplied were measured by cell deformation, i.e., $\mu$ strain (12). Four-point bending system was consisting of a computer-controlled, servomotor-driven, linear actuator assembly with an interface controller that controlled vertical displacement and actuator ram speed (Fig. 1). Cells cultured at a static station were considered a control.

Immunofluorescence analysis. Immunofluorescence staining was used to detect the cytoskeleton. Chondrocytes were prepared on vinyl bending dishes at a density of $5.0 \times 10^{4}$ cells $/ \mathrm{cm}^{2}$. Subsequent to stress loading, the chondrocytes were washed with cold PBS three times and fixed in 4\% formaldehyde for $15 \mathrm{~min}$ at room temperature, followed by permeabilization with $0.1 \%$ Triton X-100 in PBS (Sigma-Aldrich; Merck Millipore) for 10 min. F-actin was stained with a Rhodamine-phalloidin mixed solution (Life Technologies; Thermo Fisher Scientific, Inc.) for $1 \mathrm{~h}$, and after three washes with PBS, 4',6-diamidino-2-phenylindole (Sigma-Aldrich; Merck Millipore) was used to stain the nucleolus for $10 \mathrm{~min}$ at room temperature. All fluorescent staining images were taken under a confocal microscopy (LSM 710; Zeiss, Oberkochen, Germany) using a 40X oil immersion objective lens.

Alkaline phosphatase (ALP) activity assay. Cellular ALP activity was determined using the p-nitrophenyl phosphate method (LabAssay ${ }^{\mathrm{TM}}$ ALP; Wako Pure Chemical Industries, Ltd., Osaka, Japan) according to the manufacturer's instructions. The enzyme activity (units/mg protein) is equal to the concentration of p-nitrophenol $(\mathrm{nmol} / \mathrm{ml})$ that is released by the sample within $15 \mathrm{~min}$, subsequent to excluding the background. The ALP activity of each sample was normalized to the protein concentration that was detected using a Bicinchoninic Acid (BCA) protein assay kit (Pierce Biotechnology, Inc., Rockford, IL, USA).

RNA isolation and reverse transcription-quantitative polymerase chain reaction $(R T-q P C R)$. Total RNA was isolated from cultured chondrocytes using $1 \mathrm{ml}$ of TRIzol (Life Technologies; Thermo Fisher Scientific, Inc.), after the cells were compressed or submitted to agonist (blebbistatin) treatment. The total RNA was reverse transcribed according to the manufacturer's protocol, with $1 \mu \mathrm{g}$ of RNA. The RT protocol was as follows: $65^{\circ} \mathrm{C}$ for $5 \mathrm{~min}$, maintained on ice for $1 \mathrm{~min}$ at $42^{\circ} \mathrm{C}$ for $60 \mathrm{~min}, 70^{\circ} \mathrm{C}$ for $10 \mathrm{~min}$ and finally maintained at $4^{\circ} \mathrm{C}$. Reverse transcription was completed using a Tiangen RNA PCR kit (Tiangen Biotech Co., Ltd., Beijing, China). Transcriptional levels of the tested genes runt-related transcription factor 2 (RUNX2) (NC_000083.6) and MLC (NC_000073.6) were quantified by RT-qPCR with ABI Prism 7000 (Applied Biosystems; Thermo Fisher Scientific, Inc.). PCR primers are presented in Table I, and Platinum SYBR Green qPCR Super Mix-UDG (Life Technologies; Thermo Fisher Scientific, Inc.) was used. RT-qPCR was conducted in $10 \mu \mathrm{l}$ reaction mixture containing $2 \mu \mathrm{l} \mathrm{cDNA}$ samples. The thermal cycling conditions were as follows: $90^{\circ} \mathrm{C}$ for $15 \mathrm{sec}, 62.5^{\circ} \mathrm{C}$ for $15 \mathrm{sec}$, and $72^{\circ} \mathrm{C}$ for $15 \mathrm{sec}$. The RT-qPCR consisted of 40 cycles, after an initial denaturation step $\left(94^{\circ} \mathrm{C}\right.$ for $\left.2 \mathrm{~min}\right)$. The relative quantity of the mRNA level was obtained using the comparative quantification cycle $(\mathrm{Cq})$ method $\left({ }^{\Delta \Lambda} \mathrm{Cq}\right)(13)$, with glyceraldehyde 3-phosphate dehydrogenase (GAPDH) as the internal reference.

Western blot analysis. After the cells were compressed or/and treated with the agonist, protein was collected by 
Table I. Primer sequences used in reverse transcription-quantitative polymerase chain reaction.

\begin{tabular}{|c|c|c|c|c|}
\hline Gene & Forward primer & Reverse primer & Size (bp) & Accession number \\
\hline RUNX2 & 5-GCCGGGAATGATGAGAACTA-3 & 5-TGGGGAGGATTTGTGAAGAC-3 & 200 & NM 053470.2 \\
\hline MLC & 5-TCAAGAAACAGACCCCCAAG-3 & 5-CCACGATCCTCTCAAAGAGC-3 & 171 & NM 020104.2 \\
\hline ALP & 5-GACAAGAAGCCCTTCACAGC-3 & 5-ACTGGGCCTGGTAGTTGTTG-3 & 118 & NM_013059.1 \\
\hline GAPDH & 5-ATGACTCTACCCACGGCAAG-3 & 5-TACTCAGCACCAGCATCACC-3 & 76 & NC 005111.3 \\
\hline
\end{tabular}

RUNX2, runt-related transcription factor 2; bp, base pairs; MLC, myosin light chain; ALP, alkaline phosphatase; GAPDH, glyceraldehyde 3-phosphate dehydrogenase.

A

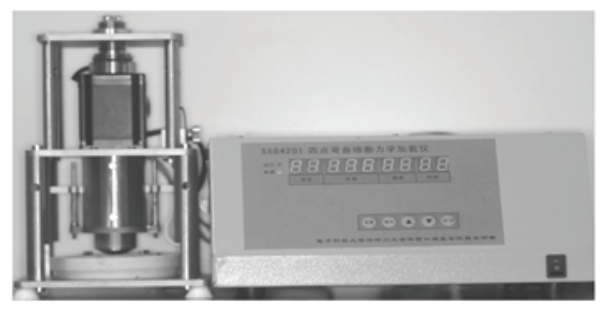

C

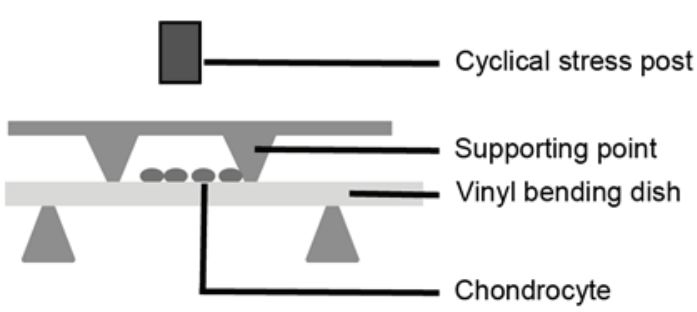

B

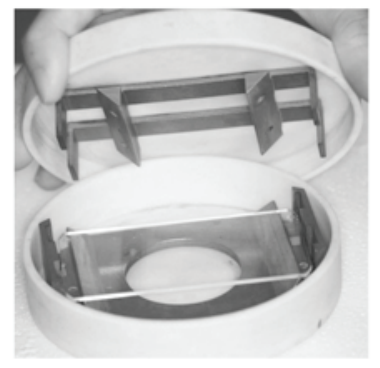

D

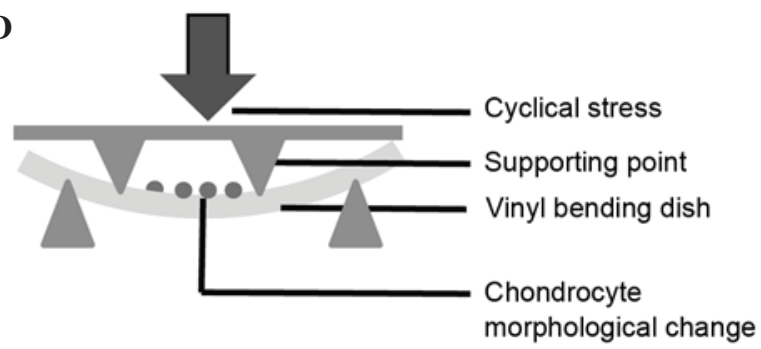

Figure 1. Photograph and ideograph of cyclical uniaxial stress apparatus. (A) Photograph of stress apparatus. (B) Vinyl bending dishes. (C and D) Schematic illustration of applying cyclical uniaxial compressive stress on cultured chondrocytes.

lysis with phosphatase inhibitor and protease inhibitor (Roche Diagnostics Corporation, Indianapolis, IN, USA). They were quantified with the BCA protein assay kit. Proteins $(30 \mu \mathrm{g})$ were separated with $10 \%$ sodium dodecyl sulfate-polyacrylamide gels, then, electrophoretically transferred to polyvinylidene difluoride membranes (Roche Diagnostics Corporation) for $2 \mathrm{~h}$. The membranes were incubated in blocking buffer [Tris-buffered saline (TBS), $0.1 \%$ Tween-20, 2\% bovine serum albumin (Sigma-Aldrich)] at room temperature for $1 \mathrm{~h}$. Subsequent to washing of the membranes 3 times in TBS ( $5 \mathrm{~min} / \mathrm{wash}$ ), they were treated with phosphorylated MLC (cat. no. 3671; 1:1,000; polyclonal rabbit anti-rat; Cell Signaling Technology, Inc., Danvers, MA, USA), total MLC (cat. no. 3672; 1:1,000; polyclonal rabbit anti-rat; Cell Signaling Technology, Inc.) and RUNX2 (cat. no. ab23981; 1:1,000; polyclonal rabbit anti-rat; Abcam) antibodies overnight at $4^{\circ} \mathrm{C}$. They were incubated with anti-rabbit IgG (cat. no. 7074; 1:2,000 dilution in TBS-T; Cell Signaling Technology, Inc. and cat. no. BA1058; 1:1,000 dilution in TBS-T; Wuhan Boster Biological Technology, Ltd., Wuhan, China) coupled with horseradish peroxidase for $1 \mathrm{~h}$ at room temperature. Protein detection was performed and visualized using Enhanced Chemiluminescence Advance
Western Blotting Detection Reagent kit (EMD Millipore, Billerica, MA, USA). Protein loading was estimated using GAPDH (cat. no. 3683; 1:2,500; polyclonal rabbit anti-rat; Cell Signaling Technology, Inc.). The intensity of the protein fragments was quantified using the ImageJ version 1.48 software (National Institutes of Health, Bethesda, MD, USA).

Selective inhibitors of signal transduction pathways. ML-7 (MLCK inhibitor, $10 \mu \mathrm{M}$; Cayman Chemical, Michigan, MI, USA) and blebbistatin (non-muscle myosin II inhibitor, $20 \mu \mathrm{M}$; Cayman Chemical) were selected to inhibit the MLC pathways. Briefly, chondrocytes were pretreated with the inhibitors individually for $1 \mathrm{~h}$ prior to the application of compression $(14,15)$. The inhibitor was also present during the 2-h CUCS treatment. Subsequently, osteogenic RUNX2 was assayed at $0 \mathrm{~h}$ (mRNA) and $24 \mathrm{~h}$ (protein). When the third passage chondrocytes seeded on vinyl bending reached $50 \%$ confluence, the transfection procedure followed using Lipofectamine $^{\mathrm{TM}}$ RNAiMAX (Invitrogen; Thermo Fisher Scientific, Inc.) with forward transfection. Briefly, 7.5 $\mu 1 \mathrm{MLC}$ RNA interference (RNAi) duplex (Guangzhou RiboBio Co., Ltd., Guangzhou, China) added to $250 \mu$ l Opti-MEM reduced serum medium without serum. A total of $2.5 \mu 1 \mathrm{RNAi}$ 


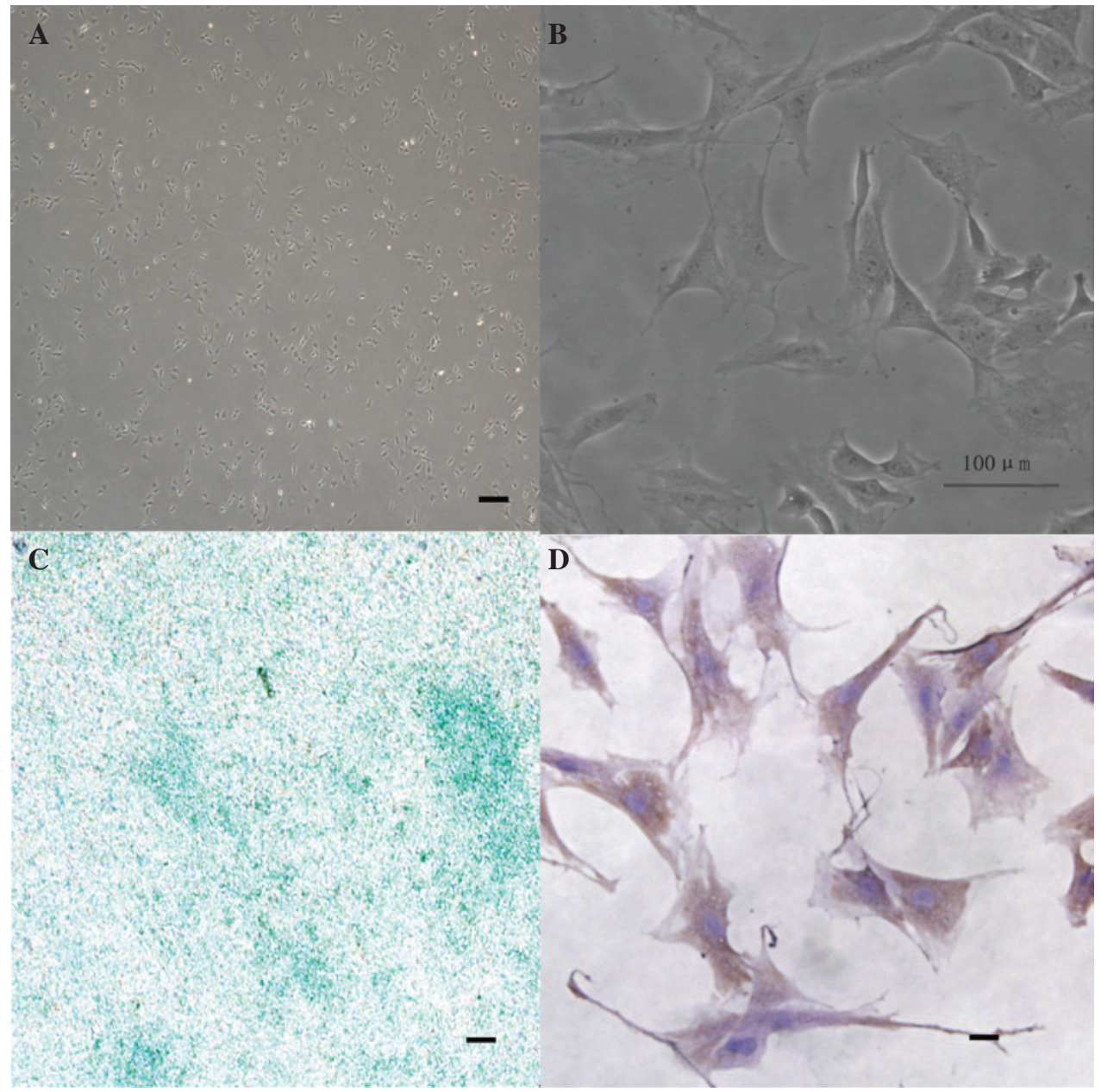

Figure 2. Identification of MCCs. (A and B) Primary MCCs showed polygonal-shaped, morphology in culture on days 6-14. (C) Photograph of glycosaminoglycan staining by alcian blue in MCCs at day 14. (D) Photograph of collagen type II immunostaining in MCCs (Scale bar $=100 \mu \mathrm{m}$ ). MCC, mandibular condylar chondrocyte.

A
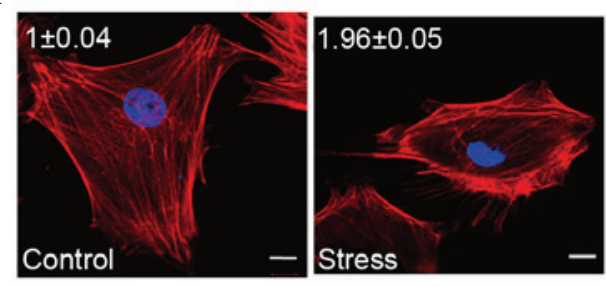

D

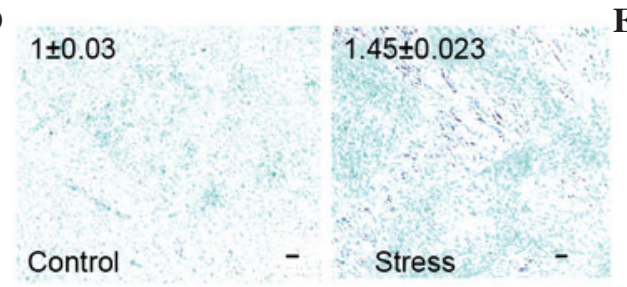

B
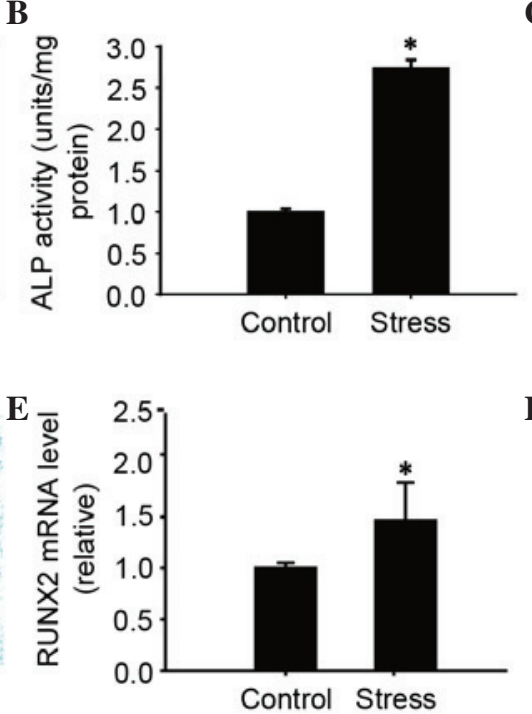

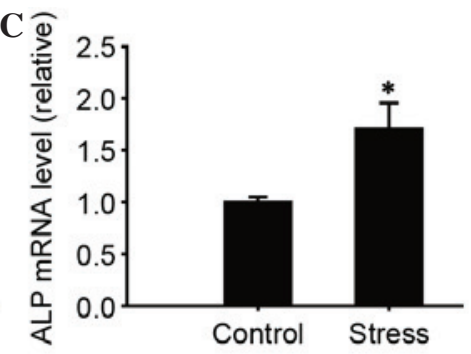

$\mathbf{F}$

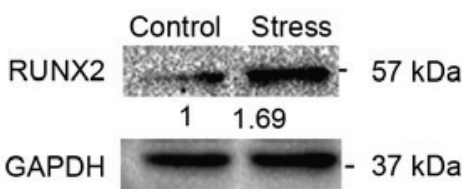

Figure 3. CUCS promoted the differentiation of MCCs. (A) The cytoskeleton stained with rhodamine-phalloidin indicated that CUCS caused cytoskeleton rearrangement. The relative means and standard deviations of the fluorescence intensities in the images are presented (scale bar, $1-\mu \mathrm{m}$ ). (B) ALP activity quantification at $48 \mathrm{~h}$ subsequent to treatment. (C) Relative quantification of ALP mRNA determined by RT-qPCR following treatment. (D) Glycosaminoglycan staining by alcian blue in MCCs following treatment with stress or control (scale bar, $1-\mu \mathrm{m}$ ). Relative integrated optical density of immunostaining was calculated. (E) Transcriptional levels of RUNX2 in chondrocytes were determined by RT-qPCR at 0 h subsequent to CUCS treatment. (F) RUNX2 protein expression was analyzed by western blot analysis at $24 \mathrm{~h}$ subsequent to treatment. Data in $\mathrm{B}-\mathrm{E}$ are presented as the mean \pm standard error; $\mathrm{n}=3$; ${ }^{*} \mathrm{P}<0.05$. CUCS, cyclical uniaxial compressive stress; MCC, mandibular condylar chondrocyte; ALP, alkaline phosphatase; RT-qPCR, reverse transcription-quantitative polymerase chain reaction; RUNX2, runt-related transcription factor 2; GAPDH, glyceraldehyde 3-phosphate dehyrdrogenase. 
A

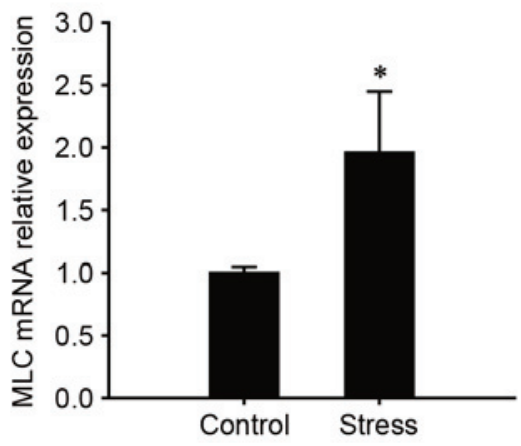

C

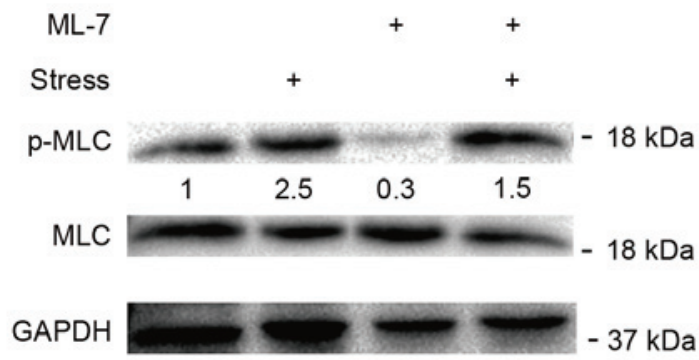

$\mathbf{E}$

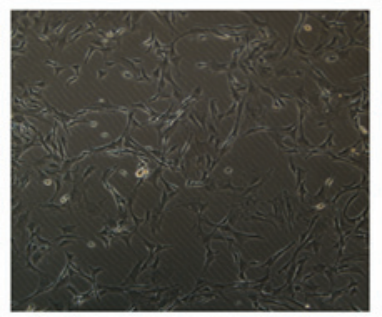

B

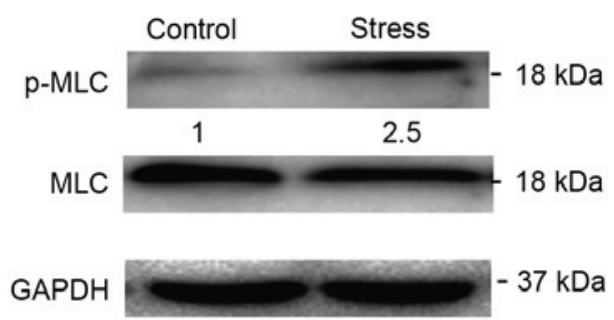

D

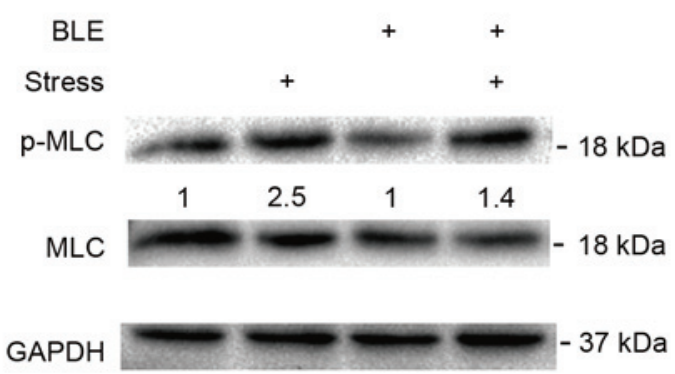

$\mathbf{F}$

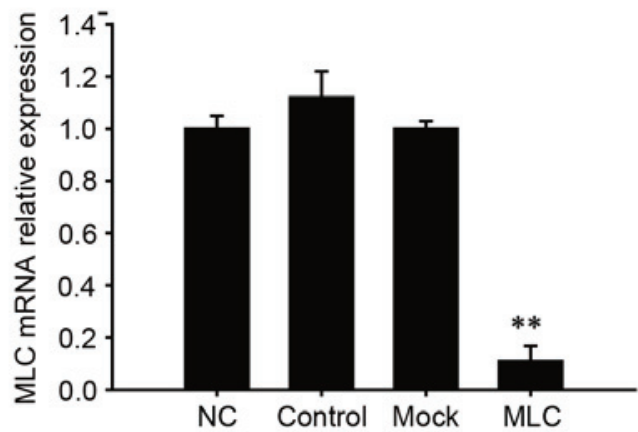

Figure 4. Involvement of MLC in cyclical uniaxial stress. (A) Transcriptional levels of MLC in chondrocytes determined by RT-qPCR at $0 \mathrm{~h}$ after treatment. (B) Western blot analysis of MLC phosphorylation following exposure of chondrocytes to CUCS or the control. (C) Alterations in p-MLC subsequent to exposure of the chondrocytes to the control, CUCS, BLE, CUCS + BLE, ML-7 and CUCS + ML-7. (D and E) MCCs subsequent to RNA interference transfection at $24 \mathrm{~h}$ (magnification, $\mathrm{x} 40$ ). Cells stained red on the right panel indicate the positively transfected cells $(\sim 85 \%)$. (F) MLC silencing efficiency was assessed. The silencing efficiency of myosin light chain was $\sim 85 \% 24 \mathrm{~h}$ post-transfection. NC group refers to cells transfected with a sequence that has no homology to the target sequence. Control group refers to untransfected cells. Mock group refers to untransfected cells treated with the transfection reagent. Data are presented as the mean \pm standard error; $n=3 ;{ }^{*} \mathrm{P}<0.05,{ }^{* *} \mathrm{P}<0.01$ compared with the NC. MLC, myocin light chain; CUCS, cyclical uniaxial compressive stress; p-, phosphorylated; BLE, blebbistatin; MCC, mandibular condylar chondrocyte; ALP, alkaline phosphatase; RT-qPCR, reverse transcription-quantitative polymerase chain reaction; RUNX2, runt-related transcription factor 2; GAPDH, glyceraldehyde 3-phosphate dehyrdrogenase; NC, culture cell with an added sequence with no homology to target sequence.

MAX (Invitrogen; Thermo Fisher Scientific, Inc.) added to $250 \mu 1$ Opti-MEM reduced serum medium without serum. They were mixed at room temperature for $10 \mathrm{~min}$, and then transferred into the cell medium without the antibody. At $12 \mathrm{~h}$ subsequent to transfection, the culture medium was replaced with fresh DMEM with $10 \%$ FBS. Transfection efficiency was estimated by immunofluorescence and RT-qPCR. The RNAi-treated cells were continually cultured after 24 or $48 \mathrm{~h}$ and used for the experiments that followed.

Statistical analysis. All data are presented as the mean \pm standard error unless otherwise stated. Statistical analysis was conducted using one-way analysis of variance or Student's t-test. $\mathrm{P}<0.05$ was considered to indicate a statistically significant difference. All of the experiments were performed in triplicate.

\section{Results}

MCCs morphology observed and identified. Polygonal-shaped, primary MCCs were observed in cultures at passage 3 (Fig. 2A and B). Induction of glycosaminoglycan (GAG) synthesis stained positively with alcian blue (Fig. 2C) and collagen type II stained positive on vinyl bending dishes (Fig. 2D). These observations indicated that the isolated cells were MCCs.

CUCS promoted chondrocyte differentiation. To investigate the potential role of myosin under CUCS, the effects of CUCS on the differentiation of chondrocytes were first evaluated. CUCS treatment was able to induce early morphological alterations in TMJ chondrocytes. Actin filaments became thicker and 
A

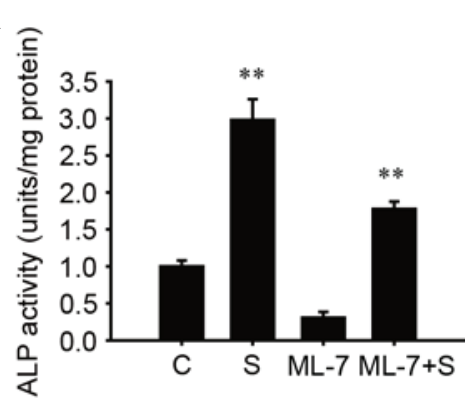

D

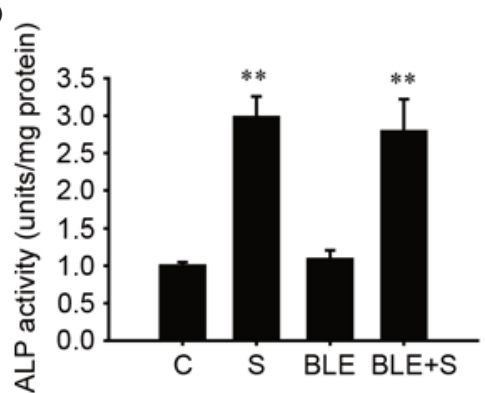

G

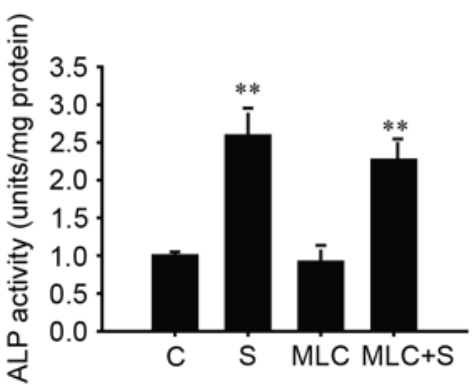

B

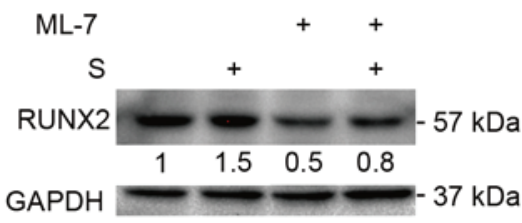

$\mathbf{E}$

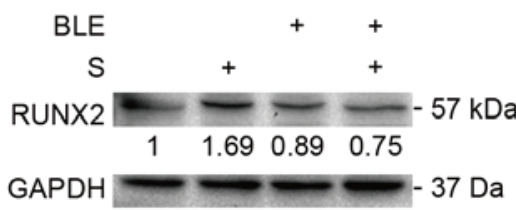

$\mathbf{H}$

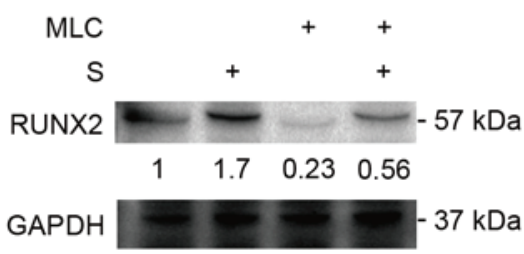

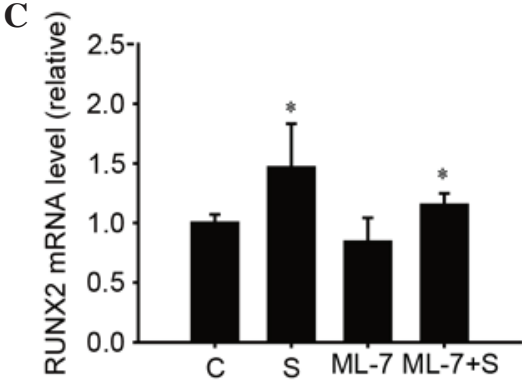

F

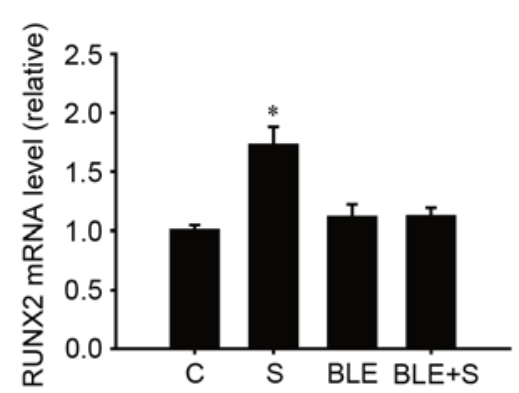

I

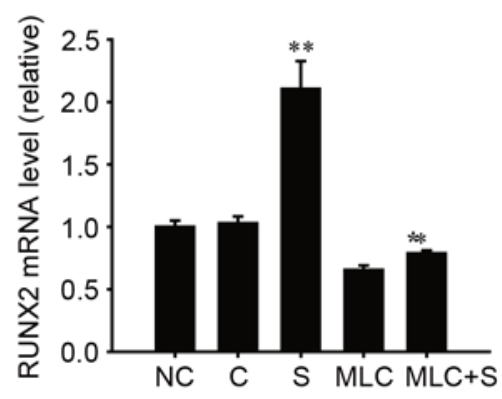

Figure 5. MLC governs CUCS-induced differentiation in MCCs. (A) ALP activity quantification at $48 \mathrm{~h}$ subsequent to involvement of ML-7 in the CUCS stress assay. (B) Western blot analysis of RUNX2 protein expression at $24 \mathrm{~h}$ subsequent to involvement of ML-7. (C) Transcriptional levels of RUNX2 in chondrocytes, determined by RT-qPCR at $0 \mathrm{~h}$ after addition of ML-7. (D) ALP activity quantification at $48 \mathrm{~h}$ subsequent to addition of BLE in the CUCS stress assay. (E) Western blot analysis of RUNX2 protein expression at $24 \mathrm{~h}$ after addition of BLE. (F) Transcriptional levels of RUNX2 in chondrocytes, determined by RT-qPCR at $0 \mathrm{~h}$ after addition of of BLE. (G) ALP activity quantification at $48 \mathrm{~h}$ after CUCS, a significant reduction was observed subsequent to CUCS with RNAi treatment. (H) Alterations in RUNX2 protein expression at $24 \mathrm{~h}$ subsequent to chondrocyte exposure to RNAi treatment. (I) Transcriptional levels of RUNX2 in chondrocytes, determined by RT-qPCR at $0 \mathrm{~h}$ with RNAi treatment. Data are presented as the mean \pm standard error; $\mathrm{n}=3$; ${ }^{*} \mathrm{P}<0.05$, ${ }^{* *} \mathrm{P}<0.01$ compared with the NC. MLC, myocin light chain; CUCS, cyclical uniaxial compressive stress; MCC, mandibular condylar chondrocyte; ALP, alkaline phosphatase; RUNX2, runt-related transcription factor 2; RT-qPCR, reverse transcription-quantitative polymerase chain reaction; BLE, blebbistatin; RNAi, RNA interference; C, control; S, stress; GAPDH, glyceraldehyde 3-phosphate dehyrdrogenase; NC, culture cell with an added sequence with no homology to target sequence.

the cells were paralleled with the orientation of the compression, compared with the random distribution of the unloaded control cells (Fig. 3A). ALP mRNA levels were observed to be upregulated immediately, which was consistent with the ALP activity observed at $48 \mathrm{~h}$ post CUCS (Fig. 3B and C). Subsequently, the GAG levels increased following CUCS (Fig. 3D). The mRNA levels of the osteogenic differentiation marker RUNX2 were increased following the CUCS treatment $(\mathrm{P}<0.01$; Fig. 3E). The protein levels of RUNX2 increased at $24 \mathrm{~h}$ subsequent to the CUCS treatment, in accordance with the gene expression $(\mathrm{P}<0.05$; Fig. 3F).

CUCS elevated the expression of TMJ chondrocyte contractile markers. It was identified that subsequent to CUCS treatment, the levels of MLC increased rapidly ( $\mathrm{P}<0.05$; Fig. 4A), while proportions of phosphorylated MLC and the total MLC increased immediately subsequent to CUCS treatment, in agreement with the gene expression results $(\mathrm{P}<0.05$; Fig. $4 \mathrm{~B})$. To test the role of the MLCK in response to CUCS, chondrocytes were treated with one of the dominant negative MLCK inhibitors (ML-7). The phosphorylation of MLC was reduced $(\mathrm{P}<0.05)$ by CUCS, compared with the non-treated control cells (Fig. 4C). To investigate the role of MLC in the response to CUCS, chondrocytes were treated with non-muscle myosin II inhibitors (blebbistatin). The inhibitor blebbistatin marginally inhibited the expression of phosphorylated MLC-II (P>0.05), while the applied stress significantly increased the expression of phosphorylated MLC-II ( $\mathrm{P}<0.05$; Fig. 4C). To further test the role of myosin, RNAi was used. The transfection efficiency was approximately $85 \%$ following $24 \mathrm{~h}$ transfection (Fig. 4D and E).

Inhibition of MLCK significantly reduced the differentiation of cultured chondrocytes. ALP activity reduced $(\mathrm{P}<0.05$; 
Fig. 5A). Similar results were observed for RUNX2 protein expression after CUCS and addition of the inhibitor (Fig. 5B). The results indicated that the inhibitor-treated cells exhibited a significant reduction in RUNX2 mRNA expression after CUCS and inhibitor treatment, as presented in Fig. $5 \mathrm{C}(\mathrm{P}<0.05)$.

Inhibition of MLC partially reduced the differentiation of cultured chondrocytes. ALP activity was upregulated $48 \mathrm{~h}$ post-CUCS $(\mathrm{P}<0.05)$, while ALP activity was altered following addition of the inhibitor and the stress treatment $(\mathrm{P}<0.05$; Fig. 5D). At the same time, RUNX2 protein expression and mRNA remained unchanged following addition of the inhibitor and stress treatment $(\mathrm{P}>0.05)$ (Fig. 5E and F). The clear increase in ALP RNAi-transfected chondrocytes was statistically significant following CUCS compared with RNAi-transfected cells (Fig. 5G). The RUNX2 protein and mRNA expression increased following addition of the RNAi and the stress treatment $(\mathrm{P}<0.05$; Fig. $5 \mathrm{H}$ and $\mathrm{I})$.

\section{Discussion}

Mechanical stress of the TMJ is commonly caused by talking, mastication or orthodontic treatment (4-6). The ability chondrocytes to respond to mechanical load is important for the maintenance of normal function of articular cartilage (16-18). Previous studies have indicated that exogenous mechanical stress may induce a series of cellular alterations including gene expression, protein phosphorylation and cellular function (19-24). In the current study, in order to simulate natural joint status, primary MCCs from rats were exposed to cyclic forces of 2,000 $\mu$ strain (12).

RUNX2 is one of the most important transcription factors of hypertrophic differentiation (25-27). It is expressed in pre-hypertrophic and hypertrophic chondrocytes, and RUNX2 has been reported to promote chondrocyte hypertrophy prior to endochondral ossification (28). In RUNX2 knockout mice, a previous study observed that bone maturation was delayed $(29,30)$. Overexpression of RUNX2 induces hypertrophic differentiation (31), and it was reported that stress may increase the expression of RUNX2 in human chondrocytes (32). In the current study, the mRNA and protein levels of RUNX2 were identified to be significantly upregulated following CUCS treatment.

ALP is predominantly expressed in hypertrophic chondrocytes (33) and it is commonly used as a marker for osteogenic differentiation. In ALP knockout mice, a previous study observed that cartilage mineralization was reduced (34) and additional studies reported that stress increased ALP activity in MC3T3 cells (35) and human periodontal ligament cells (36). The results of the current study demonstrated that CUCS promoted the differentiation of primary MCCs in vitro, indicated by significantly increased expression levels of RUNX2 and increased ALP activity.

It has been previously demonstrated that the cytoskeleton is associated with mechanical stress (37-39). In the present study, it was observed that cytoskeletal rearrangement occurred immediately subsequent to CUCS treatment, with part of the actin filaments accumulating together around the cell membrane. Li et al (11) reported that cytoskeletal rearrangement was induced with higher levels of stress $(4,000 \mu$ strain) compared with that used in the current study $(2,000 \mu$ strain $)$.
It is suggested that the age of rat may affect the ability of the chondrocytes to sense and respond to different level of exogenous mechanical stress (40). The viscoelastic properties of older cells are commonly lower than that of younger cells (41) and it has been reported that the cytoskeleton is closely linked with with cellular differentiation-associated proteoglycan and collagen synthesis in chondrocytes (42). In the present study, when the cytoskeleton was disrupted with cytochalasin D, the differentiation associated with alterations of the MCCs was observed to be significantly reduced, indicating that the cytoskeleton was involved in signal transduction of MCCs in the experimental system (data not shown).

MLC-II has been demonstrated to control actomyosin contractility in various types of cells (43), and phosphorylated MLC-II adjusts the activity of bone cells and acts as an important effector of cell function $(44,45)$. In drosophila, the differentiation of cells has been inhibited by replacing phosphorylated MLC-II with MLC-II (46). In the current study, silencing MLC-II using RNAi resulted in downregulation of chondrocyte differentiation, as presented by the reduction in ALP activity and RUNX2 mRNA levels. This indicated that MLC-II serves an important role in MCC differentiation. The MLCK inhibitor, ML-7, aimed to inhibit the phosphorylation of MLC-II, and induced a reduction of ALP activity and downregulation of RUNX2 expression. Taken together, the results suggest that CUCS promotes rat primary MCC differentiation through phosphorylated MLC-II.

The four-point bending system used in the current study provides an in vitro model for the study of cellular responses to mechanical stress. The signaling transferred from outside mechanical stress to inside of cells was also reported to be responsible by monolayer chondrocyte. Sanz-Ramos et al (47) described that the expression levels of integin $\alpha 1, \beta 1$ and $\beta 3$ in monolayer chondrocytes were sensitive to matrix stiffness, similar to the response of 3D-cultured chondrocytes, however this mechanism remains unclear. In the current study, the chondrocytes cultured on the slides were monolayer, however it remains unclear whether the culture strategy may influence how these cells perceive mechanical signals. Further study with chondrocytes subjected to compressive strain cultured in $3 \mathrm{D}$ matrices may address this issue.

\section{Acknowledgements}

The current study was supported by Grants from the National Natural Science Foundation of China (grant no. 81070860) and the Natural Science Foundation of Guangdong Province (grant no. s2013010016753). The authors would like to thank Professor Guangmei Yan (Sun Yat-sen University) and his group for providing technical support.

\section{References}

1. Maruthamuthu V, Aratyn-Schaus Y and Gardel ML: Conserved F-actin dynamics and force transmission at cell adhesions. Curr Opin Cell Biol 22: 583-588, 2010.

2. Papusheva E and Heisenberg CP: Spatial organization of adhesion: Force-dependent regulation and function in tissue morphogenesis. EMBO J 29: 2753-2768, 2010.

3. Sarasa-Renedo A, Tunç-Civelek V and Chiquet M: Role of RhoA/ROCK-dependent actin contractility in the induction of tenascin-C by cyclic tensile strain. Exp Cell Res 312: 1361-1370, 2006. 
4. Tanaka E and van Eijden T: Biomechanical behavior of the temporomandibular joint disc. Crit Rev Oral Biol Med 14: $138-150,2003$.

5. Mori H, Horiuchi S, Nishimura S, Nikawa H, Murayama T, Ueda K, Ogawa D, Kuroda S, Kawano F, Naito H, et al: Three-dimensional finite element analysis of cartilaginous tissues in human temporomandibular joint during prolonged clenching. Arch Oral Biol 55: 879-886, 2010.

6. Kuroda S, Tanimoto K, Izawa T, Fujihara S, Koolstra JH and Tanaka E: Biomechanical and biochemical characteristics of the mandibular condylar cartilage. Osteoarthritis Cartilage 17: $1408-1415,2009$

7. Tanaka E, Sasaki A, Tahmina K, Yamaguchi K, Mori Y and Tanne K: Mechanical properties of human articular disk and its influence on TMJ loading studied with the finite element method. J Oral Rehabil 28: 273-279, 2001.

8. Hu K, Radhakrishnan P, Patel RV and Mao JJ: Regional structural and viscoelastic properties of fibrocartilage upon dynamic nanoindentation of the articular condyle. J Struct Biol 136: 46-52, 2001.

9. Walsh AJ and Lotz JC: Biological response of the intervertebral disc to dynamic loading. J Biomech 37: 329-337, 2004.

10. Ronziere MC, Roche S, Gouttenoire J, Démarteau O, Herbage D and Freyria AM: Ascorbate modulation of bovine chondrocyte growth, matrix protein gene expression and synthesis in three-dimensional collagen sponges. Biomaterials 24: 851-861, 2003.

11. Li H, Yang HS, Wu TJ, Zhang XY, Jiang WH, Ma QL, Chen YX, $\mathrm{Xu} \mathrm{Y,} \mathrm{Li} \mathrm{S} \mathrm{and} \mathrm{Hua} \mathrm{ZC:} \mathrm{Proteomic} \mathrm{analysis} \mathrm{of} \mathrm{early-response}$ to mechanical stress in neonatal rat mandibular condylar chondrocytes. J Cell Physiol 223: 610-622, 2010.

12. Owan I, Burr DB, Turner CH, Qiu J, Tu Y, Onyia JE and Duncan RL: Mechanotransduction in bone: Osteoblasts are more responsive to fluid forces than mechanical strain. Am J Physiol 273: C810-C815, 1997.

13. Livak KJ and Schmittgen TD: Analysis of relative gene expression data using real-time quantitative PCR and the 2(-Delta Delta C(T)) method. Methods 25: 402-408, 2001.

14. Saitoh M, Ishikawa T, Matsushima S, Naka M and Hidaka $H$ Selective inhibition of catalytic activity of smooth muscle myosin light chain kinase. J Biol Chem 262: 7796-7801, 1987.

15. Engler AJ, Sen S, Sweeney HL and Discher DE: Matrix elasticity directs stem cell lineage specification. Cell 126: 677-689, 2006.

16. Wu M, Xu T, Zhou Y, Lu H and Gu Z: Pressure and inflammatory stimulation induced increase of cadherin-11 is mediated by PI3K/Akt pathway in synovial fibroblasts from temporomandibular joint. Osteoarthritis Cartilage 21: 1605-1612, 2013.

17. Palmoski MJ, Colyer RA and Brandt KD: Joint motion in the absence of normal loading does not maintain normal articular cartilage. Arthritis Rheum 23: 325-334, 1980.

18. Kiviranta I, Jurvelin J, Tammi M, Säämänen AM and Helminen HJ: Weight bearing controls glycosaminoglycan concentration and articular cartilage thickness in the knee joints of young beagle dogs. Arthritis Rheum 30: 801-809, 1987.

19. Wong M, Siegrist M and Goodwin K: Cyclic tensile strain and cyclic hydrostatic pressure differentially regulate expression of hypertrophic markers in primary chondrocytes. Bone 33: 685-693, 2003

20. Heyland J, Wiegandt K, Goepfert C, Nagel-Heyer S, Ilinich E, Schumacher U and Pörtner R: Redifferentiation of chondrocytes and cartilage formation under intermittent hydrostatic pressure. Biotechnol Lett 28: 1641-1648, 2006.

21. Batra NN, Li YJ, Yellowley CE, You L, Malone AM, Kim CH and Jacobs CR: Effects of short-term recovery periods on fluid-induced signaling in osteoblastic cells. J Biomech 38: 1909-1917, 2005

22. Liedert A, Kaspar D, Blakytny R, Claes L and Ignatius A: Signal transduction pathways involved in mechanotransduction in bone cells. Biochem Biophys Res Commun 349: 1-5, 2006.

23. Sibonga JD, Zhang M, Evans GL, Westerlind KC, Cavolina JM, Morey-Holton E and Turner RT: Effects of spaceflight and simulated weightlessness on longitudinal bone growth. Bone 27 : $535-540,2000$

24. Wong M and Carter DR: Articular cartilage functional histomorphology and mechanobiology: A research perspective. Bone 33: $1-13,2003$.

25. Wuelling $\mathrm{M}$ and Vortkamp A: Chondrocyte proliferation and differentiation. Endocr Dev 21: 1-11, 2011.

26. Ding M, Lu Y, Abbassi S, Li F, Li X, Song Y, Geoffroy V, Im HJ and Zheng Q: Targeting Runx2 expression in hypertrophic chondrocytes impairs endochondral ossification during early skeletal development. J Cell Physiol 227: 3446-3456, 2012.
27. Zhang S, Xiao Z, Luo J, He N, Mahlios J and Quarles LD: Dose-dependent effects of Runx2 on bone development. J Bone Miner Res 24: 1889-1904, 2009.

28. Goldring MB, Tsuchimochi K and Ijiri K: The control of chondrogenesis. J Cell Biochem 97: 33-44, 2006.

29. Ducy P, Zhang R, Geoffroy V, Ridall AL and Karsenty G: Osf2/Cbfa1: A transcriptional activator of osteoblast differentiation. Cell 89: 747-754, 1997.

30. Komori T, Yagi H, Nomura S, Yamaguchi A, Sasaki K, Deguchi K, Shimizu Y, Bronson RT, Gao YH, Inada M, et al: Targeted disruption of Cbfa1 results in a complete lack of bone formation owing to maturational arrest of osteoblasts. Cell 89: 755-764, 1997.

31. Komori T: Regulation of skeletal development by the Runx family of transcription factors. J Cell Biochem 95: 445-453, 2005.

32. Saito T, Nishida K, Furumatsu T, Yoshida A, Ozawa M and Ozaki T: Histone deacetylase inhibitors suppress mechanical stress-induced expression of RUNX-2 and ADAMTS-5 through the inhibition of the MAPK signaling pathway in cultured human chondrocytes. Osteoarthritis Cartilage 21: 165-174, 2013.

33. Pfander D, Swoboda B and Kirsch T: Expression of early and late differentiation markers (proliferating cell nuclear antigen, syndecan-3, annexin VI, and alkaline phosphatase) by human osteoarthritic chondrocytes. Am J Pathol 159 1777-1783, 2001.

34. Mackie EJ, Ahmed YA, Tatarczuch L, Chen KS and Mirams M: Endochondral ossification: How cartilage is converted into bone in the developing skeleton. Int J Biochem Cell Biol 40: 46-62, 2008.

35. Mai Z, Peng Z, Wu S, Zhang J, Chen L, Liang H, Bai D, Yan G and $\mathrm{Ai} \mathrm{H}$ : Single bout short duration fluid shear stress induces osteogenic differentiation of MC3T3-E1 cells via integrin $\beta 1$ and BMP2 signaling cross-talk. PLoS One 8: e61600, 2013.

36. Tang M, Peng Z, Mai Z, Chen L, Mao Q, Chen Z, Chen Q, Liu L, Wang Y and Ai H: Fluid shear stress stimulates osteogenic differentiation of human periodontal ligament cells via the extracellular signal-regulated kinase $1 / 2$ and p38 mitogen-activated protein kinase signaling pathways. J Periodontol 85: 1806-1813, 2014.

37. Durrant LA, Archer CW, Benjamin M and Ralphs JR: Organisation of the chondrocyte cytoskeleton and its response to changing mechanical conditions in organ culture. J Anat 194: 343-353, 1999.

38. Broom ND and Myers DB: A study of the structural response of wet hyaline cartilage to various loading situations. Connect Tissue Res 7: 227-237, 1980.

39. Ohashi N, Robling AG, Burr DB and Turner $\mathrm{CH}$ : The effects of dynamic axial loading on the rat growth plate. J Bone Miner Res 17: 284-292, 2002.

40. Chahine NO, Blanchette C, Thomas CB, Lu J, Haudenschild D and Loots GG: Effect of age and cytoskeletal elements on the indentation-dependent mechanical properties of chondrocytes. PLoS One 8: e61651, 2013.

41. Duan W, Wei L, Zhang J, Hao Y, Li C, Li H, Li Q, Zhang Q, Chen W and Wei X: Alteration of viscoelastic properties is associated with a change in cytoskeleton components of ageing chondrocytes from rabbit knee articular cartilage. Mol Cell Biomech 8: 253-274, 2011.

42. Mallein-Gerin F, Garrone R and van der Rest M: Proteoglycan and collagen synthesis are correlated with actin organization in dedifferentiating chondrocytes. Eur J Cell Biol 56: 364-373, 1991.

43. Alenghat FJ and Ingber DE: Mechanotransduction: All signals point to cytoskeleton, matrix and integrins. Sci STKE 2002: pe6, 2002.

44. Matsumura F and Hartshorne DJ: Myosin phosphatase target subunit: Many roles in cell function. Biochem Biophys Res Commun 369: 149-156, 2008

45. Goeckeler ZM, Bridgman PC and Wysolmerski RB: Nonmuscle myosin II is responsible for maintaining endothelial cell basal tone and stress fiber integrity. Am J Physiol Cell Physiol 295: C994-C1006, 2008.

46. Jordan P and Karess R: Myosin light chain-activating phosphorylation sites are required for oogenesis in Drosophila. J Cell Biol 139: 1805-1819, 1997.

47. Sanz-Ramos P, Mora G, Ripalda P, Vicente-Pascual M and Izal-Azcárate I: Identification of signalling pathways triggered by changes in the mechanical environment in rat chondrocytes. Osteoarthritis Cartilage 20: 931-939, 2012. 